\title{
GENETIC POLYMORPHISMS OF GLUTATHIONE S- TRANSFERASE (M1 AND T1) AND PARAOXONASE 1 (PON1) AND SUSCEPTIBILITY TO CHRONIC KIDNEY DISEASE OF UNKNOWN ETIOLOGY IN PESTICIDE EXPOSED PATIENTS AT ZAGAZIG UNIVERSITY HOSPITALS
}

\author{
Omaima I. Abdel Hamid", Dalia I.A. Mesallam', Amira E Abdel-Salam², Ahmed Ahmed \\ Mohammed Zaghlol ${ }^{3}$ \\ Forensic Medicine \& Clinical Toxicology ${ }^{1}$, Community Medicine ${ }^{2}$ and internal medicine ${ }^{3}$ \\ Departments, Faculty of Medicine, Zagazig University
}

\begin{abstract}
Background: Pesticide compounds are commonly used worldwide and in Egypt. Chronic low level exposure of humans to these compounds has resulted in many health adverse effects. There are many reports relating chronic kidney disease of unknown etiology $(\mathrm{CKDu})$ epidemic to pesticide exposure including organophosphates (OP). Glutathione-S-transferase mu (GSTM1) and glutathione-S-transferase theta (GSTT1) are phase II xenobiotic metabolizing enzymes. Paraxonase 1 (PON1) is an enzyme linked to high-density lipoprotein. It can prevent oxidation of low-density lipoproteins and participates in organophosphate detoxification. Objective: To investigate the association of genetic polymorphism of GST (M1, T1) and PON1 Q192R with CKDu in pesticide exposed patients presented to Nephrology Unit, Internal Medicine Department, Zagazig University Hospitals, Sharkia Governorate. Methods: Gas chromatography- mass spectrometry (GC-MS) was used for detection of dialkyl phosphate metabolites in urine samples of subjects included in the study then genomic DNA isolated from the blood samples of $48 \mathrm{CKDu}$ patient chronically exposed to pesticides giving positive result for dialkyl phosphate metabolites and matched control group was used to detect the presence or absence of the GSTM1 and GSTT1 genes (gene deletion) by multiplex polymerase chain reaction technique (multiplex PCR) and PON1 polymorphisms using polymerase chain reaction-restriction fragment length polymorphism (PCR-RFLP) method. Conclusion: This study suggested that there is a correlation between chronic exposure to organophosphates and the risk of CKDu due to GSTM1 and GSTT1 genes deletions and PON1 gene polymorphisms.
\end{abstract}

Keywords: Glutathin S transferase, Paraoxonase, Chronic kidney disease of unknown etiology, Polymorphism

\section{INTRODUCTION}

Chronic kidney disease of unknown etiology $(\mathrm{CKDu})$ represents about $10 \%$ of CKD patients globally (Siddarth et al., 2015). An elevated prevalence of $\mathrm{CKDu}$ in agricultural communities, predominantly among male farmworkers has been reported in Central America,
Egypt, India and Sri Lanka (Almaguer et al., 2014). In Egypt, the cause of end stage renal disease (ESRD) is unknown in $27 \%$ of patients (Kamell and ElMinshawy, 2010 \& El-Minshawy, 2011a).

Diabetes and hypertension constitute the major risk elements for chronic kidney 
disease (CKD) worldwide. In low income countries, glomerulonephritis is also important (Barsoum, 2006). Nevertheless, in the last two decades, a severe type of CKD has been defined in patients without these risk factors. CKD of unknown etiology (CKDu) involves adults in the third to fifth decade of life and is frequently lethal due to disease progress in addition to deficiency of dialysis or transplantation in the concerned geographic regions (Weaver et al., 2015).

Though the triggers of $\mathrm{CKDu}$ have not been settled conclusively, there is growing evidence incriminating agricultural compounds (Jayasinghe, 2014). A case control study of ESRD Egyptian patients established a correlation with rural residence and pesticide exposure (El-Minshawy, 2011b)

Efforts to decrease pesticide exposure through the use of further technologies to control pests and organic agricultural practices continue, however exposure to pesticides occupationally and through residue in domestic dust, and in foodstuff and water is widespread (Michael and Alavanja, 2009).

In Egypt, where agricultural activities account for $28 \%$ of total national income, great risks of pesticide exposure was found due to incorrect application techniques, the use of toxic chemicals which are banned or restricted in other areas, inadequate storage practices, inadequately maintained or totally improper spraying equipment and even the reuse of old pesticide bottles for storing food and water (Ibitayo, 2006). EL-Sharqia governorate is considered an agricultural community where organophosphate is the most common type of pesticide used (Isawi, 2012).

There are several previous reports of organophosphate induced nephrotoxicity,
Malathion induced immune-complex nephropathy has been reported by Albright (1984). In addition, Wedin (1992) suggested that Malathion possibly have direct toxic effect on renal tubules and they can alter renal function significantly due to alteration in neural, humoral and metabolic activity. PeirisJohn et al. (2006) also suggests a possible association between CRFu, acetycholine esterase levels and long term low-level exposure to organophosphates.

The metabolism of most $\mathrm{OP}$ compounds yields six terminal products that are excreted in urine; they are termed dialkylphosphates (DAP). They involve dimethyl group including: dimethylphosphate (DMP), dimethylthiophosphate (DMTP), dimethyldithiophosphate (DMDTP), and diethyl group including: diethylphosphate (DEP), diethylthiophosphate (DETP) and diethyldithiophosphate

(DEDTP)

(Wessels et al., 2003). Urinary DAP metabolites give valuable data about accumulative exposure to $\mathrm{OP}$ pesticides (Barr et al., 2004). They are currently used as a biomarker of human exposure to organophosphorus insecticides (Forsberg et al., 2011).

Closely related to biomarkers of exposure are the biomarkers of susceptibility which determine the individual responses to environmental toxicants and vulnerability to toxicantinduced diseases (Au et al., 1999).

Organophosphates are primarily metabolized in the liver through hepatic cytochrome P450 3A4 and 3A5 (Phase I enzyme) to produce the active intermediate organophosphorus-oxon. Phase II metabolizing enzymes include glutathione S-transferases (GST) which are considered a major group of detoxifying enzymes (Wong et al., 2006). In addition, organophosphorus-oxon may 
then be hydrolyzed by paraoxonase (PON) to diethyl phosphate (DEP) and 4nitrophenol, or conjugated to glutathione (GSH) (Barr et al., 2004).

The polymorphic genotypes of the enzymes GST and paraoxonase-1 involved in the metabolism and detoxification of pesticides including organophosphates and their impact on disease susceptibility were studied for certain disorders as parkinsonism (Narayan et al., 3013), preterm delivery (Banerjee et al., 2014) and DNA damage and cancer (Kapka-Skrzypczak et al., 2011), however their association with $\mathrm{CKDu}$ is rarely studied.

\section{THE AIM OF THE STUDY}

To investigate the association of genetic polymorphism of GST (M1, T1) and PON1 Q192R with CKDu in pesticide exposed patients presented to Nephrology Unit, Internal Medicine Department, Zagazig University Hospitals, Sharkia Governorate.

\section{SUBJECTS AND METHODS}

This work was conducted through a case control study. The design of the study was approved by the Ethical Committee of Faculty of Medicine, Zagazig University. All subjects were of Egyptian nationality. After explanation of the research objectives and procedures and ensuring complete confidentiality of data, a signed written informed consent was obtained from each subject before participation.

Cases of chronic kidney disease, defined by criteria described by Kidney Disease Improving Global Outcomes (KDIGO, 2013) who were admitted to Nephrology Unit of Internal Medicine Department, Faculty of Medicine, Zagazig University during period from June 2015 to December 2016 (total number 400 cases) were asked to answer a questionnaire that include demographic data (age, sex, residence), occupation, history of any medical disease.

\section{Exclusion criteria: Diabetes,} hypertension, any previous renal disease or infection, previous operations, exposure to snake bite, medications used (appendix 1).

Out of the four hundred cases of chronic kidney disease, one hundred and ten cases were found to meet the criteria of CKDu. CKDu was identified based on the criteria settled by the Scientific Committee of the National Research Program for CKDu commenced by World Health Organization in collaboration with the Ministry of Healthcare and Nutrition in Sri Lanka (Research program for CKDu in Sri Lanka, 2009).

Cases of $\mathrm{CKDu}$ occupationally exposed to pesticide and not yet on dialysis were the target of our study (58 cases). They were subjected to urine sample in order to detect organophosphorus metabolites which considered as valuable data about accumulative exposure to organophosphorus (identify exposure), then subjected to blood sample for assessment and investigation of genetic polymorphism of GST (M1, T1) and PON1 Q192R with CKDu in pesticide exposed patients.

A similar number of age, sex and occupation matched healthy subjects were recruited as a control group. Control group was chosen from healthy individuals coming with the patients and hospital team putting in mind not to involve direct relatives of the patients. Age matching was done in 5 years intervals.

\section{I- Detection of organophosphorus metabolites in urine:}


For each subject included in the study $10 \mathrm{ml}$ of first morning void urine was collected in a polypropylene container (Kissel et al., 2005). The containers were prewashed in $10 \%$ nitric acid for more than 3 hours and then rinsed twice in purified water. The samples were stored at $-20^{\circ} \mathrm{C}$ for organophosphorus metabolite detection. According to Tarbah et al., (2004), DAP metabolites are stable under storage at $-20{ }^{\circ} \mathrm{C}$. Preparation was performed according to the method described by Hardt and Angerer (2000). Briefly, before analysis urine was thawed and the internal standard was added. The internal standard was prepared by dissolving $50 \mathrm{mg}$ dibutylphosphate in 50 $\mathrm{mL}$ methanol then diluted with water to produce a concentration of $10 \mathrm{mg} / \mathrm{L}$. Then, HCL was used for acidification followed by two cycles of liquid/liquid extraction with 1:1 mixture of diethyl ether and acetonitrile. The organic layer was vaporized until desiccation and the deposit was thawed in dehydrated acetonitrile. The DAP metabolites were derivatized using pentafluorobenzyl bromide (PFBBr). Water and hexane were added and the DAPs were shifted to the hexane portion by shaking the tubes. The hexane portion was concentrated and analyzed with GC-MS.

The GC-MS analysis was performed in Central Lab of the National Research Centre, El-Dokki, Cairo. Helium was used as a carrier gas with splitless injection of $1 \mu \mathrm{L}$. The temperature programming was as follows: injection port temperature was $260^{\circ} \mathrm{C}$; column $90^{\circ} \mathrm{C}$ for $1 \mathrm{~min}$, then raised at a rate $25^{\circ} \mathrm{C} / \mathrm{min}$ to $120^{\circ} \mathrm{C}$ and maintained for 2 minutes, raised at $6^{\circ} \mathrm{C} / \mathrm{min}$ to $180^{\circ} \mathrm{C}$ and maintained for 25 minutes than raised at a rate of $10^{\circ} \mathrm{C} / \mathrm{min}$ to $250^{\circ} \mathrm{C}$ and isothermal for $34 \mathrm{~min}$; transfer line temperature $300^{\circ} \mathrm{C}$. Mass spectrometer was operated in electron impact (EI) ionization with electron energy of $70 \mathrm{eV}$; multiplier $2300 \mathrm{~V}$; selected ion monitoring (SIM) mode.

\section{II-DNA extraction:}

For each participant, two milliliter of venous blood was collected in EDTAtreated tubes analysis and stored at $-20^{\circ} \mathrm{C}$ until analysis. The samples were coded the analysis was blind. Genomic DNA extraction was performed using FavorPrep Blood Genomic DNA Extraction Mini Kit (Cat.No. FABGK 001) from Favorgen Biotech Corp.; following the manufacturer's instructions.

\section{III- Genetic analysis: \\ GSTT1 and GSTM1 genes deletions detection:}

GSTT1 and GSTM1 genes deletions was verified using multiplex polymerase chain reaction (PCR) according to the technique described by Arand et al., (1996). The primer pairs for GSTT1 gene was: forward 5'-TTC CTT ACT GGT CCT CAC ATC TC-3' and reverse 5'TCA CCG GAT CAT GGC CAG CC-3', while the primer pairs for GSTM1 gene was: forward 5'-GAA CTC CCT GAA AAG CTA AAG C-3' and reverse 5'-GTT GGG CTC AAA TATA CGG TGG-3'. The internal control used was albumin gene with forward 5' - GCC CTC TGC TAA CAA GTC CTA C-3' and reverse 5'-GCC CTA AAA AGA AAA TCG CCA ATC-3'. The protocol of amplification was one cycle $95^{\circ} \mathrm{C}$ for 2 minutes then 30 cycles of $94^{\circ} \mathrm{C}$ for 1 minute followed by $64^{\circ} \mathrm{C}$ for 1 minute, $72^{\circ} \mathrm{C}$ for 1 minute. The final extension included a cycle of $72^{\circ} \mathrm{C}$ for 5 minutes. The multiplex PCR analysis of GSTT1 and GSTM1 genes are presented in figure (I) where the wild genotype of GSTM1 is presented as a band of $215 \mathrm{bp}$ and the wild genotype of GSTT1 is presented as a band of $480 \mathrm{bp}$. No bands were detected with GSTM1, GSTM1 null genotypes 
(homozygous absence or deletion). Albumin used as internal positive control (show 350 bp band), in order to discriminate the null genotype from aborted PCR reactions.

\section{PON1 genotype analysis:}

The genotypes of PON1 gene was analyzed by polymerase chain reactionrestriction fragment length polymorphism (PCR-RFLP) according to the method described by Humbert et al. (1993) and Zama et al. (1997). The primer used for amplification was forward: 5-TAT TGT TGC TGT GGG ACC TGA G-3` and reverse: 5 -CAC GCT AAA CCC AAA TAC ATC TC-3'. The amplification was achieved using a thermal cycler PTC-100 machine (MJ Research, Inc., Watertown, MA). Initial denaturation at $95^{\circ} \mathrm{C}$ for 5 minutes was first carried out followed by 35 cycles composed of $95^{\circ} \mathrm{C}$ for 1 minute, $58^{\circ} \mathrm{C}$ (PON192 fragment) for 1 minute and $72^{\circ} \mathrm{C}$ for 1 minute followed lastly by a final step of extension of $72^{\circ} \mathrm{C}$ for 7 minutes. For Q192R genotyping, ten microliters of PCR product was digested with 3 units of the restriction enzyme NlaIII and 8 units of the restriction enzyme AlwI (New England Biolabs) at $37^{\circ} \mathrm{C}$ for 5 hours. The PCR genotyping was done in a total amount of $25 \mu \mathrm{l}$ composed of $100 \mathrm{ng}$ of template DNA, $12.5 \mu \mathrm{l}$ of $2 \mathrm{X}$ i-TaqTM PCR Master Mix (iNtRON Biotechnology) and 25 pmol of each primer (Biosearch Technologies, Novato, CA).

The PON192 Q (glutamine) allele was assigned through the presence of a 99 bp (undigested) fragment while $\mathrm{R}$ (argenine) was assigned by the presence of $33 \mathrm{bp}$ (digested) fragment. Control DNA samples with identified genotypes were involved in each run to insure accurate genotype detection.

The PON1 PCR products were split in a 3\% agarose electrophoresis system from Maxicell, EC 360 M-E-C Apparatus Corporation, St. Petersburg, FL. UV trans-illumination with 100-bp SiZerTM DNA marker (iNtRON Biotechnology) was used for visualization after staining with ethidium bromide as shown in figure II.

\section{Statistical analysis}

Data were collected, tabulated, and managed using Statistical Package for Social Science version 16 (SPSS Inc., Chicago, IL). Chi square was used to estimate the statistical significance of dialkyl phosphate metabolites detection in urine of patients. The odds ratio (OR) and its $95 \%$ confidence interval $(95 \% \mathrm{CI})$ was estimated to assess the strength of the association between genotypes, alleles and disease risk. $\mathrm{P}$ value less than 0.05 was considered statistically significant.

\section{RESULTS}

As shown in table (1), analysis of the socio-demographic information of the 110 cases of chronic kidney disease of unknown etiology presented to Nephrology Unit of Internal Medicine Department, Zagazig University Hospitals from June 2015 to December 2016 revealed that their age ranges from 20 to 50 years, males presents $54.5 \%$ of the total number. $63.6 \%$ of cases live in rural areas and $52.7 \%$ are occupationally exposed to pesticides.

\section{Organophosphorus metabolites in urine:}

As shown in table (2), GC-MS analysis of urine samples revealed that $48(82.7 \%)$ of cases have detectable DAPs compared to $16(27.5 \%)$ of controls. Whereas population who showed positive results for OP metabolites in urine were subjected to DNA extraction and genotyping.

Analysis of GSM1and GSTT1 gene deletions and risk of CKDu: 
The frequencies of genotype were adapted to the Hardy-Weinberg equilibrium in patients $(\mathrm{P}=0.932)$ and in controls $(\mathrm{P}=0.917)$. The distribution of GSTM1 genotypes and allele frequencies in $\mathrm{CKDu}$ patients and controls were presented in table (3). Out of total 48 patients, the GSTM1 null allele was detected in 35 (72.9\%) and the GSTM1 wild alleles was detected in $13(27.1 \%)$. Of the 16 control subjects, the null allele was found in $5(31.2 \%)$, wild GSTM1 present in $11(68.8 \%)$. The difference was statistically significant $(\mathrm{p}=0.007)$ and the Odds ratio was 5.9 with $95 \%$ confidence interval 1.7-20.3

The GSTT1 genotype distribution and allele frequencies in CKDu patients and controls were presented in table (4). Out of total $48 \mathrm{CKDu}$ patients, GSTT1 null allele was observed in 29 $(60.4 \%)$ and the wild alleles was observed in $19(39.6 \%)$. Of the 16 controls, GSTT1 null allele was observed in 4 subjects (25\%), GSTT1 present in 12 subjects (75\%). The difference was statistically significant $(\mathrm{p}=0.03)$ and the Odds ratio was 4.5 with $95 \%$ confidence interval 1.2-16.3

\section{Analysis of PON1 Q192R polymorphism:}

The Q192R genotypes distribution was also harmonious with HardyWeinberg equilibrium in $\mathrm{CKDu}$ patients $(\mathrm{P}=0.791)$ and in controls $(\mathrm{P}=$ 0.710). The PON1 Q192R genotype distribution and allele frequencies is shown in table (5) where QQ (homozygous), QR (heterozygous) and RR (homozygous mutated) were observed in $27.1 \%, 14.5 \%$ and $58.4 \%$ of $\mathrm{CKDu}$ patients respectively versus $68.7 \%, 12.5 \%$ and $18.8 \%$ in control subjects respectively. The $\mathrm{R}$ mutated allele was detected in $65.6 \%$ of $\mathrm{CKDu}$ patients and $25 \%$ of controls. Regarding the risk of CKDu development, the QQ wild genotype and $Q$ wild allele were taken as references. The study revealed that subjects who are QR heterozygotes showed no risk for CKDu (OR 0.8, 95\% CI 0.1 - 4.5, $\mathrm{P}=0.6$ ) while RR homozygotes, and $\mathrm{R}$ allele showed high risk for $\mathrm{CKDu}$ (OR 0.1, 95\% CI 0.04$0.6, \mathrm{P}=0.01)(\mathrm{OR} 5.7,95 \%$ CI 2.314.1, $\mathrm{P}=0.0001)$ respectively. 
Table (1): Socio-demographic characteristics of cases of chronic kidney disease of unknown etiology

\begin{tabular}{|l|c|c|}
\hline Variables & Number & $\%$ \\
\hline Age & $35 \pm 15$ & \\
\hline Sex & & \\
-Males & 60 & 54.5 \\
-Females & 50 & 45.5 \\
\hline Residence & & \\
-urban & 40 & 36.4 \\
-rural & 70 & 63.6 \\
\hline occupation & & \\
-Exposed to pesticide & 58 & 52.7 \\
-Not exposed to pesticide & 52 & 47.3 \\
\hline Duration of pesticide exposure & & \\
- 0 & 52 & 47.3 \\
-less than 10 years & 14 & 12.7 \\
-10 years or more & 44 & 40.0 \\
\hline Total & 110 & $100 \%$ \\
\hline
\end{tabular}

Table (2): statistical comparison of detectable dialkyl phosphate metabolites in urine between cases of CKDu and controls using Chi- square test

\begin{tabular}{|c|c|c|c|c|c|}
\hline & \multicolumn{2}{|c|}{ CKDu patients } & \multicolumn{2}{c|}{ Controls } & \multirow{2}{*}{ P value } \\
\cline { 2 - 5 } & Number & \% & Number & \% & \\
\hline Detectable DAPs & 48 & 82.7 & 16 & 27.5 & \multirow{2}{*}{0.000} \\
\hline Non -detectable DAPs & 10 & 17.3 & 42 & 72.5 & \\
\hline Total & 58 & 100 & 58 & 100 & \\
\hline
\end{tabular}

P $<$ 0.05: statistically significant.

Table (3): Statistical comparison of the genotype distribution of the GSTM1 in CKDu patients and controls using Chi-square test

\begin{tabular}{|c|c|c|c|c|c|c|}
\hline \multirow{2}{*}{ Group } & \multicolumn{2}{|c|}{ CKDu cases } & \multicolumn{2}{c|}{ control } & \multirow{2}{*}{ P } & \multirow{2}{*}{ OR (95\% CI) } \\
\cline { 2 - 5 } & Number & $\boldsymbol{\%}$ & Number & \% & & \\
\hline Present & 13 & 27.1 & 5 & 31.2 & \multirow{2}{*}{0.007} & $5.9(1.7-20.3)$ \\
\hline null & 35 & 72.9 & 11 & 68.8 & & \\
\hline Total & 48 & 100 & 16 & 100 & & \\
\hline
\end{tabular}

P < 0.05: statistically significant $\quad$ CI: confidence interval $\quad$ OR:odds ratio

Table (4): Statistical comparison of the genotype distribution of GSTT1 in CKDu patients and controls using Chi-square test

\begin{tabular}{|c|c|c|c|c|c|c|}
\hline \multirow{2}{*}{ GSTT1 } & \multicolumn{2}{|c|}{ CKDu cases } & \multicolumn{2}{|l|}{ control } & \multirow[t]{2}{*}{$\mathrm{P}$} & \multirow{2}{*}{$\begin{array}{l}\text { OR } \\
\text { CI) }\end{array}$} \\
\hline & Number & $\%$ & Number & $\%$ & & \\
\hline Present & 19 & 39.6 & 12 & 75 & \multirow[t]{3}{*}{0.03} & \multirow{3}{*}{$\begin{array}{l}4.5 \\
16.3)\end{array}$} \\
\hline null & 29 & 60.4 & 4 & 25 & & \\
\hline Total & 48 & 100 & 16 & 100 & & \\
\hline
\end{tabular}

P $<$ 0.05: statistically significant $\quad \mathrm{OR}=$ odds ratio $\quad \mathrm{CI}=$ confidence interval 
Table (5): Statistical comparison of the distribution of PON1 Q192R allele and genotype frequencies in CKDu patients and the controls using Chi-square test

\begin{tabular}{|c|c|c|c|c|c|c|}
\hline \multirow{2}{*}{ PON1 Q192R } & \multicolumn{2}{|c|}{ CKDu cases } & \multicolumn{2}{|c|}{ control } & \multirow[t]{2}{*}{$\mathrm{P}$} & \multirow[t]{2}{*}{ OR $(95 \% \mathrm{CI})$} \\
\hline & Number & $\%$ & Number & $\%$ & & \\
\hline Genotypes & & & & & \multirow{3}{*}{------- } & \multirow{5}{*}{$\begin{array}{c}1.0 \text { (reference) } \\
0.8(0.1-4.5) \\
0.1(0.04-0.6)\end{array}$} \\
\hline QQ & 13 & 27.1 & 11 & 68.7 & & \\
\hline QR & 7 & 14.5 & 2 & 12.5 & & \\
\hline $\mathrm{RR}$ & 28 & 58.4 & 3 & 18.8 & \multirow[t]{2}{*}{0.01} & \\
\hline Total & 48 & 100 & 16 & 100 & & \\
\hline Alleles & & & \multirow{3}{*}{24} & & \multirow{2}{*}{0.0001} & \multirow{2}{*}{$\begin{array}{c}1.0(\text { reference }) \\
5.7(2.3-14.1)\end{array}$} \\
\hline Q & 33 & $\begin{array}{c}34.4 \\
65.6\end{array}$ & & 75.0 & & \\
\hline$\frac{\mathrm{R}}{\text { Total }}$ & $\frac{03}{96}$ & $\begin{array}{r}05.0 \\
100\end{array}$ & & $\frac{25.0}{100}$ & & \\
\hline 1 otal & 30 & 100 & & & $-\infty$ & 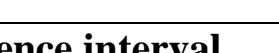 \\
\hline
\end{tabular}

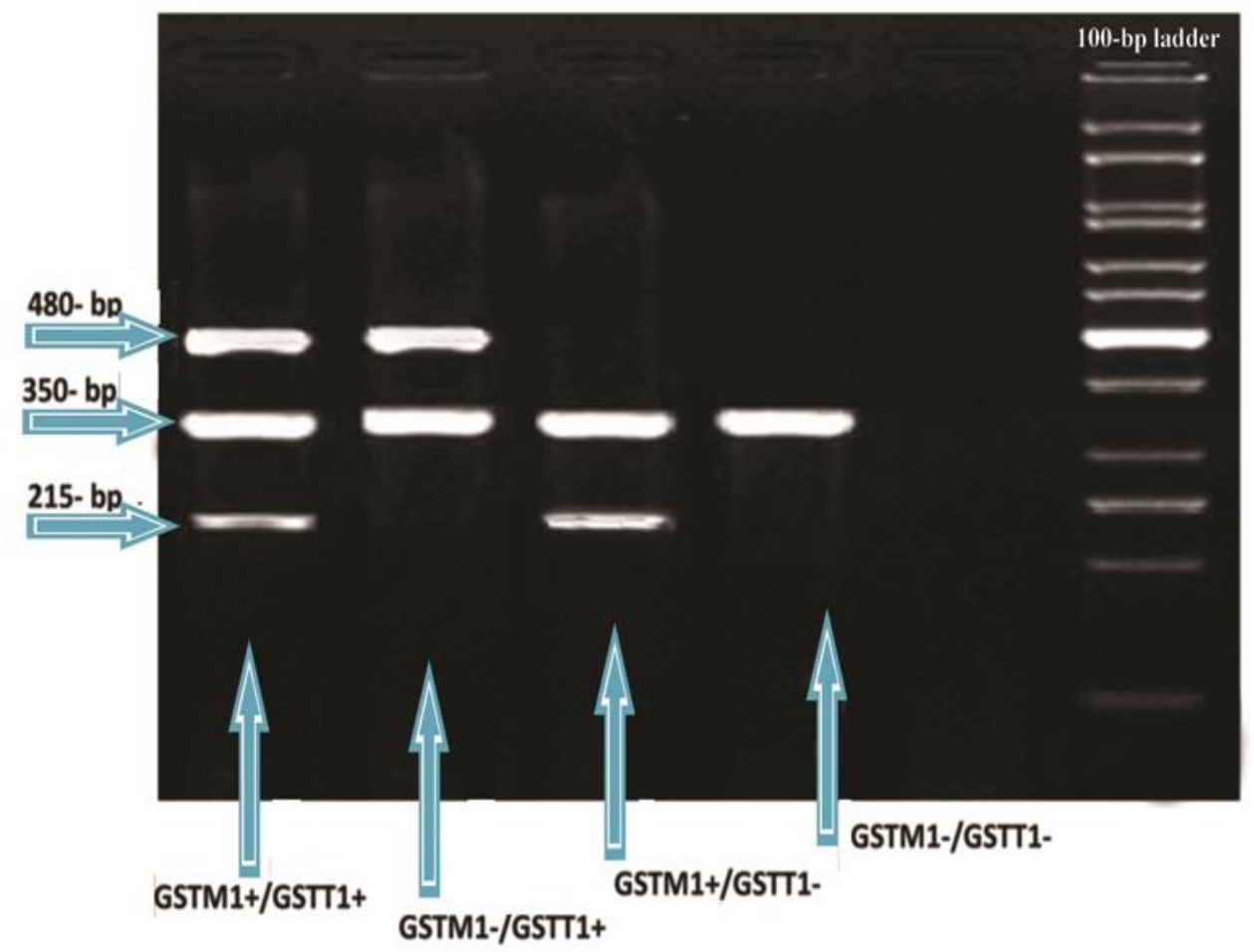

Figure (I): Multiplex PCR patterns for GSTM1 and GSTT1 genes. 


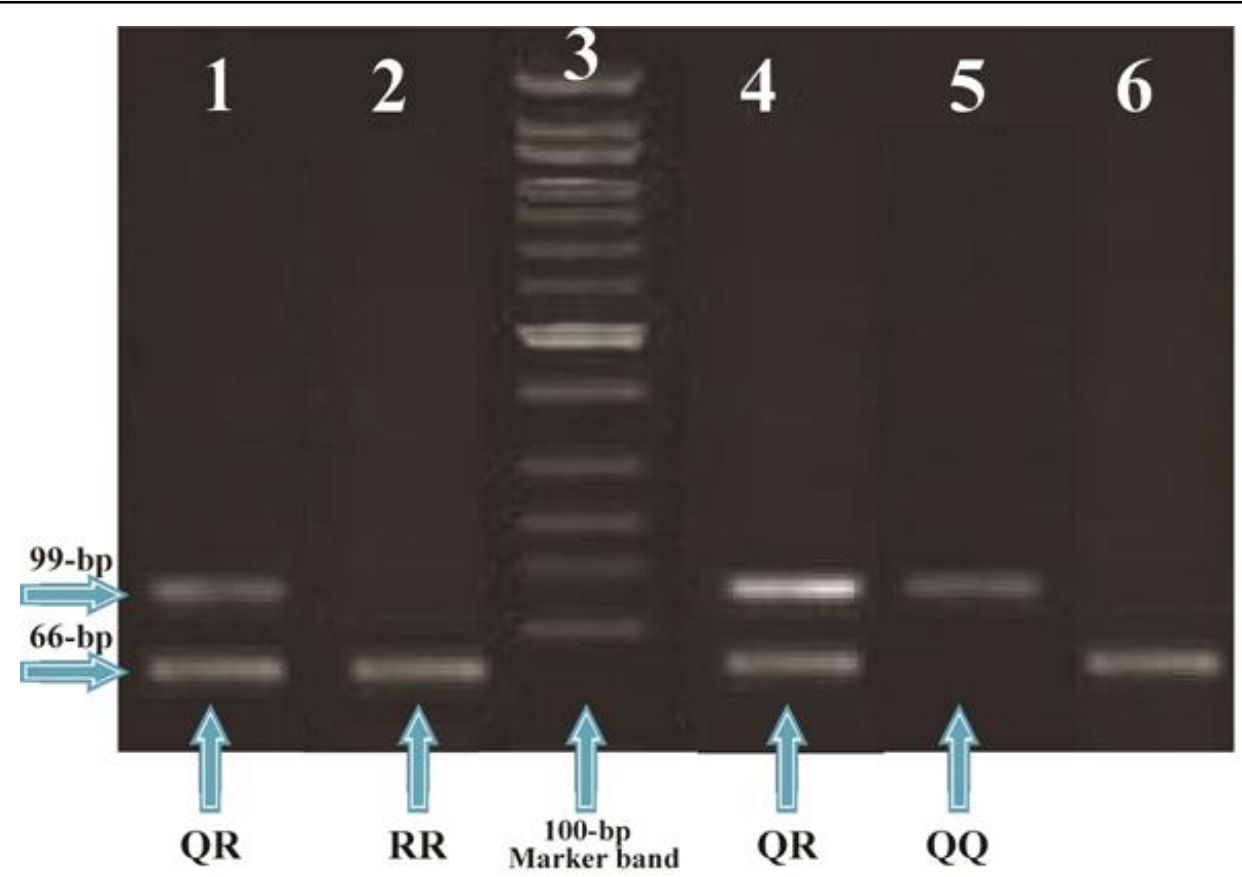

Figure (II): Agarose gel electrophoresis showing the bands pattern obtained by polymerase chain reaction restriction fragment length polymorphism (PCR-RFLP) for genotyping the PON1 Q192R polymorphism; lane 1, 4 for QR with 99-bp and 66-bp bands; lane 2 for RR with 66-bp; Lane 5 contains a 99-bp represent QQ genotype; and 44-bp (not shown) bands and lane 3, contains a 100-bp marker bands.

\section{DISCUSSION}

Numerous current studies have attracted attention to the appearance of an epidemic of CKD not ascribed to ordinary etiologies such as hypertension, diabetes, obstructive uropathy or glomerulonephritis in Central America, southern Asia and Egypt (Jayatilake et al., 2013). Jayasinghe (2014) stated that risk of $\mathrm{CKDu}$ increases with rural agricultural work and agrochemical exposure; hence the condition should be retitled chronic agrochemical nephropathy to emphasize the likely etiology. The aim of the present work was to investigate the association of genetic polymorphism of GST (M1, T1) and PON1 Q192R with $\mathrm{CKDu}$ in pesticide exposed patients.

In the current work 110 cases met the criteria of $\mathrm{CKDu}$; analysis of the socio-demographic data of those patients demonstrated that they ranged from 20 to 50 years in age which correlates with the mean age of $\mathrm{CKDu}$ patients in other areas of the world as India, Sri Lanka and Central America (Almaquer et al., 2014; Wijetunge et al., 2015). Prevalence was generally higher in male subjects and those living in rural areas in accordance with Kamel and El-Minshawy (2010); Weaver et al. (2015). Among those occupationally exposed to pesticide it was found that a higher proportion of patients were exposed for 10 years or more; coinciding with these results Valcke et al. (2017) found in his review some evidence of association between pesticides exposure and $\mathrm{CKDu}$, more clearly in studies with stronger design and better exposure assessment.

In the current work urinary dialkyl phosphate metabolite was used as a 
marker of chronic exposure to organophosphate compounds. Although red blood cell choline esterase activity can also be used as a marker of chronic exposure to organophosphates, it has the advantage of difficult interpretation due to inter- and intra-individual variation and the absence of baseline values for individuals (Wessels et al., 2003). According to Meeker et al. (2005) urinary organophosphate metabolites are often the preferred method for monitoring exposure because sample collection is easy and non-invasive and they are measured easily. In addition, Cocker et al. (2002) stated that urinary organophosphate metabolites are more sensitive than choline esterase activity because it can be detected at lower levels of exposure.

Out of fifty eight cases of CKDu included in the study, forty eight showed positive urinary dialkyl phosphate metabolites coinciding with Jayatilake et al. (2013) who reported increase in urinary pesticide residues above reference levels in $31.6 \%$ of $\mathrm{CKDu}$ cases. In addition, some scientists have shown that water in endemic areas of $\mathrm{CKDu}$ is heavily contaminated with pesticides and their residues (Jayasumana et al., 2014).

Our work declared that there is a significant correlation between GSTM1, GSTT1 null genotypes and development of $\mathrm{CKDu}$ in patients chronically exposed to organophosphates. In accordance with these results Agrawal et al. (2007) stated that the null / low polymorphism of the detoxifying enzymes GSTT1, GSTM1, and GSTP1 are linked to increasing risk of developing ESRD in North Indian patients. In addition, GutiérrezAmavizca et al. (2013) reported GSTM1 null genotype in $61 \%$ of ESRD patients. Null polymorphism represents the homozygous deletion of the gene (Peddireddy et al., 2016). As GSTM1 and GSTT1 are entangled in handling lipid peroxidation products, reactive oxygen species and various central metabolites of toxic substances, there is hypothetical relation between genetic polymorphism of those enzymes and the developing chronic diseases (Cilensek et al., 2012). Datta et al. (2010) detected that GSTM1 and GSTT1 genes deletion was associated with higher oxidative stress and lower GST levels in non-diabetic and diabetic chronic kidney disease. Moreover, according to Singh et al. (2011a) and Tumer et al. (2016) GSTM1 null genotype was associated with higher incidence of DNA damage in workers occupationally exposed to pesticides compared to controls; they correlated this to the affection of metabolism of these chemicals by the genetic variation of glutathione Stransferases. Also, higher DNA damage was detected in pesticide exposed subjects with GSTT1 gene deletion or concurrent deletion of GSTT1 and GSTM1 (Abhishek et al. (2010).

This work detected that subjects chronically exposed to OP and PON1 Q192R heterozygous showed no risk for developing $\mathrm{CKDu}$ while RR homozygous showed high risk for $\mathrm{CKDu}$.

PON1 192 RR genotype was also previously found to have an association with other chronic diseases as type 2 diabetes mellitus (El-Lebedy et al., 2014). In addition, Li et al. (2006) reported that workers occupationally exposed to lead who are homozygous for the $\mathrm{R}$ allele are more susceptible to lead toxicity than are subjects of other genotypes 
Human paraoxonase $1(\mathrm{PON} 1)$ is an enzyme linked to lipoprotein and implicated in the detoxification of chemicals as organophosphate pesticide compounds by hydrolyzing the bioactive oxons. Polymorphism of the PON1 gene is responsible for discrepancy in the expression and catalytic activity of PON1 enzyme (Singh et al., 2011b). Significantly decreased PON1 activity was found in chronic kidney disease (CKD) and renal transplant patients (Paragh et al., 2009). Kamal et al. (2011) reported that among the different paraoxonase genotypes of lead exposed workers, the enzyme activity was reported to be lowest in RR type. In contrast, Singh et al. (2011b) reported that the PON1 activity was found to be significantly higher in the $R / R$ genotypes. The cause for these disagreeing findings may be the broad inter-ethnic variability in PON1 polymorphism noticed in these researches (Rahmani et al., 2002).

PON1 has gained great attention after the recognition of its antioxidant characters, especially its ability to protect low density lipoprotein from oxidative damage (El-Lebedy et al., 2014). According to Prakash et al. (2010) enhancement and maintenance PON1 activity may have antiatherogenic role and may prevent its complication in patients with chronic renal failure.

\section{CONCLUSION}

This work suggested the presence of an association between GSTM1 and GSTT1 null genotypes and PON 1 gene polymorphism and developing CKDu in patients occupationally exposed to organophosphates. Additional studies searching for more possible underlying mechanisms clarifying the pathogenesis of $\mathrm{CKDu}$ are necessary, which will allow the prediction of individuals at risk.

\section{CONFLICTS OF INTEREST}

No conflict of interest.

\section{RERERENCES}

Abhishek, S.; Kaur, N.; Kaur, S.; et al. (2010): Association of GSTM1 and GSTT1 Gene Deletions with Susceptibility to DNA Damage in the Pesticide-Exposed Workers of Punjab. Rejuvenation Research, 13(2-3): 281-284

Agrawal, S.; Tripathi, G.; Khan, F.; et al. (2007): Relationship between GSTs gene polymorphism and susceptibility to end stage renal disease among North Indians. Renal Failure, 29:947-53

Albright, R.K. (1984): Renal involvement in organophosphate poisoning. Journal of the American Medical Association, 252: 1408

Almaquer, M. Herrera, R. and Orantes, C.M. (2014): Chronic kidney disease of unknown etiology in agricultural communities. MEDICC Review, 16(2):9-15

Arand, M.; Muhlbauer, R.; Hengstler, J.; et al. (1996): A multiplex polymerase chain reaction protocol for the simultaneous analysis of the glutathione Stransferase GSTM1 and GSTT1 polymorphisms. Anal Biochem., 236: $184-186$

Au, W.W.; Sierra-Torres, C.H.; Cajas-Salazar, N.; et al. (1999): Cytogenetic effects from exposure to mixed pesticides and the influence from genetic susceptibility. Environ Health Perspect.,107:501-5 
Banerjee, M.D.; Mustafa, M.D.; Sharma, T.; et al. (2014): Assessment of Toxicogenomic Risk Factors in Etiology of Preterm Delivery. Reprod Syst Sex Disord., 3(2):129-139

Barr, D.B.; Bravo, R.; Weerasekera, G.; et al. (2004): Concentrations of dialkyl phosphate metabolites of organophosphorus pesticides in the U.S. population. Environ Health Perspect, 112(2):186-200

Barsoum, R.S. (2006): Chronic kidney disease in the developing world. $\mathrm{N}$ Engl J Med, 354(10):997-9

Cilensek. I.; Mankoc, S.; Petrovi, M.G.; et al. (2012): GSTT1 null genotype is a risk factor for diabetic retinopathy in Caucasians with type 2 diabetes, whereas GSTM1 null genotype might confer protection against retinopathy. Disease Markers, 32: 93-99

Cocker, J.; Mason, H.J.; Garfitt, S.; et al. (2002): Biological monitoring of exposure to organophosphate pesticides. Toxicol Lett., 134:97103

Datta, S.K.; Kumar, V.; Pathak, R.; et al. (2010): Association of glutathione S-transferase M1 and T1 gene polymorphism with oxidative stress in diabetic and non-diabetic chronic kidney disease. Renal Failure, 32(10): 1189-1195

El-Lebedy, D.; Kafoury, M.; Abd-El Haleem, D.; et al. (2014): Paraoxonase-1 gene Q192R and L55M polymorphisms and risk of cardiovascular disease in Egyptian patients with type 2 diabetes mellitus. J Diabetes Metab Disord., 13: 124

El-Minshawy, O. (2011a): End stage renal disease in El-Minia Governorate, Egypt: Data of the year 2007. Nephro-Urol Monthly, 3(2):118-21

El-Minshawy, O. (2011b): End stage renal disease in the El-Mina Governorate. Upper Egypt: an epidemiological study. Saudi J Kidney Dis Transpl., 22(5):1048-54

Forsberg, N.D.; Rodriguez-Proteau, R.; Ma, L.; et al. (2011): Organophosphorus pesticide degradation product in vitro metabolic stability and time-course uptake and elimination in rats following oral and intravenous dosing. Xenobiotica, 41(5): 422429

Gutiérrez-Amavizca, B.E.; OrozcoCastellanos, R.; Ortíz-Orozco, R.; et al. (2013): Contribution of GSTM1, GSTT1, and MTHFR polymorphisms to end-stage renal disease of unknown etiology in Mexicans. Indian J Nephrol., 23(6): 438-443

Hardt, J. and Angerer, J. (2000): Determination of dialkyl phosphates in human urine using gas chromatography- mass spectrometry. Journal of analytical toxicology, 24:678-684

Humbert, R.; Adler, D.A.; Disteche, C.M.; et al. (1993): The molecular basis of the human serum paraoxonase activity polymorphism. Nat. Genet., 3:73-76

Ibitayo, O.O. (2006): Egyptian rural farmers' attitudes and behaviors regarding agricultural pesticides: Implications for pesticide risk communication. Risk Anal., 26:989995

Isawi, A. (2012): The current status of agricultural inputs in Egypt coated from marketing of main farm inputs in al-Sharkia., 2:113-116 
Jayasinghe, S. (2014): Chronic kidney disease of unknown etiology should be renamed chronic agrochemical nephropathy. MEDICC Review, 16 (2): $72-74$

Jayasumana, C.; Gajanayake, R. and Siribaddana, S. (2014): Importance of arsenic and pesticides in epidemic chronic kidney disease in Sri Lanka. BMC Nephrol., 15: 124

Jayatilake, N.; Mendis, S.; Maheepala, P.; et al. (2013): Chronic kidney disease of uncertain aetiology: prevalence and causative factors in a developing country. BMC Nephrol., 14:180

Kamal, M.; Fathy, M.M.; Taher, E.; et al. (2011): Assessment of the role of paraoxonase gene polymorphism (Q192R) and paraoxonase activity in the susceptibility to atherosclerosis among lead-exposed workers. Ann Saudi Med., 31(5): 481-487

Kamell, E.G. and El-Minshawy, O. (2010): Environmental factors incriminated in the development of endstage renal disease in El- Mina Governorate, Upper Egypt. Int J Nephrol Urol., 2(3):431-7

Kapka-Skrzypczak, L.; Cyranka, M.; Skrzypczak, M.; et al. (2011): Bio monitoring and biomarkers of organophosphate pesticides exposure - state of the art. Ann Agric Environ Med., 18(2):294-303

Kdigo (2013): Clinical practice guideline for the evaluation and management of chronic kidney disease. Kidney Int. Suppl., 3(1):1150

Kissel, J.C.; Curl, C.L.; Kedan, G.; et al. (2005): Comparison of organophosphorus pesticide metabolite levels in single and multiple daily urine samples collected from preschool children in Washington State. J Expo Anal Environ Epidemiol., 15:164-71

Li, W.F.; Pan, M.H.; Chung, M.C.; et al. (2006): Lead Exposure Is Associated with Decreased Serum Paraoxonase 1 (PON1) Activity and Genotypes. Environ. Health Perspect., 114:1233-6

Meeker, J.D.; Barr, D.B.; Ryan, L.; et al. (2005): Temporal variability of urinary levels of non-persistent insecticides in adult men. J Expo Anal Environ Epidemiol., 15:27181

Michael, C.R. (2009): Pesticides Use and Exposure Extensive Worldwide. Rev Environ Health, 24(4): 303-309

Narayan, S.; Liew, Z.; Paul, K.; et al. (2013): Household organophosphorus pesticide use and Parkinson's disease. Int J Epidemiol., 42(5):1476-85

Paragh, G.; Seres, I.; Harangi, M.; et al. (2009): Discordance in Human Paraoxonase-1 Gene between Phenotypes and Genotypes in Chronic Kidney Disease. Nephron Clin Pract., 113:c46-c53

Peddireddy, V.; Badabagni, S.P.; Gundimeda, S.D.; et al. (2016): Association of CYP1A1, GSTM1 and GSTT1 gene polymorphisms with risk of non-small cell lung cancer in Andhra Pradesh region of South India. Eur J Med Res., 21: 17

Peiris-John, R.J.; Wanigasuriya, J.K.; Wickremasinghe, A.R.; et al. (2006): Exposure to acetylcholinesterase-inhibiting pesticides and chronic renal failure. Ceylon Med J., 51:42-3

Prakash, M.; PHani, N.M.; Kavya, R. and Supriya, M. (2010): Paraoxonase: Its antiatherogenic 
role in chronic renal failure. Indian $\mathbf{J}$ Nephrol., 20(1): 9-14.

Rahmani, M.; Raiszadeh, F.; Allahverdian, S.; et al. (2002): Coronary artery disease is associated with the ratio of apolipoprotein A-I/B and serum concentration of apolipoprotein B, but not with paraoxonase enzyme activity in Iranian subjects. Atherosclerosis., 162: 381-9.

Research Programme for Chronic Kidney Disease of Unknown Aetiology in Sri Lanka [Last accessed on 2015 May 19]. Available from: http://www.epid.gov.lk/web/pdf/w er_2009/vol_36_no_49_english.pdf

Siddarth, M.; Datta, S.K.; Mustafa, M.; et al. (2014): Increased level of organochlorine pesticides in chronic kidney disease patients of unknown etiology: role of GSTM1/GSTT1 polymorphism. Chemosphere, 96:174-179

Singh, S.; Kumar, V.; Singh, P.; et al. (2011a): Genetic polymorphisms of GSTM1, GSTT1 and GSTP1 and susceptibility to DNA damage in workers occupationally exposed to organophosphate pesticides. Mutat Res., 725(1-2):36-42

Singh, S.; Kumar, V.; Thakur, S.; et al. (2011b): Paraoxonase-1 genetic polymorphisms and susceptibility to DNA damage in workers occupationally exposed to organophosphate pesticides. Toxicol. Appl. Pharmacol., 252: 130-137

Tarbah, F.A.; Kardel, B.; Pier, S.; et al. (2004): Acute poisoning with phosphamidon: Determination of dimethyl phosphate (dmp) as a stable metabolite in a case of organophosphate insecticide intoxication. J Anal Toxicol., 28:198-203

Tumer, T.B.; Savranoglu, S.; Atmaca, P.; et al. (2016): Modulatory role of GSTM1 null genotype on the frequency of micronuclei in pesticide-exposed agricultural workers. Toxicol Ind Health, 32(12):1942-1951

Valcke, M.; Levasseur, M-E.; de Silva, A.S. and Wesseling, C. (2017): Pesticide exposures and chronic kidney disease of unknown etiology: an epidemiologic review. Environ Health.; 16: 49.

Weaver, V.M.; Fadrowski, J.J. and Jaar, B.G. (2015): Global dimensions of chronic kidney disease of unknown etiology (CKDu): a modern era environmental and/or occupational nephropathy? BMC Nephrology, 16: $145-153$

Wedin, G.P. (1992): Nephrotoxicity of anticholinesterases. In: Ballantyne, B.; Marrs, T.C. (eds.) Clinical and Experimental Toxicology of Organophosphates and Carbamates. Oxford: Butterworth-Heinemann, 195-202

Wessels, D.; Barr, D.B. and Mendola, P. (2003): Use of Biomarkers to Indicate Exposure of Children to Organophosphate Pesticides: Implications for a Longitudinal Study of Children's Environmental Health. Environ Health Perspect., 111:1939-1946

Wijetunge, S.; Ratnatunga, N.V.I.; Abeysekera, T.D.J.; et al. (2015): Endemic chronic kidney disease of unknown etiology in Sri Lanka: Correlation of pathology with clinical stages. Indian J Nephrol., 25(5): 274-280 
Wong, R.H.; Chang, S.Y.; Ho, S.W.;

et al. (2008): Polymorphisms in metabolic GSTP1 and DNA-repair $\mathrm{XRCC} 1$ genes with an increased risk of DNA damage in pesticideexposed fruit growers. Mutat Res., 654:168-75

Zama, T.; Murata, M.; Matsubara, Y.; et al. (1997): A 192 Arg variant of the human paraoxonase (HUMPONA) gene polymorphism is associated with an increased risk for coronary artery disease in the Japanese. Arterioscler Thromb Vasc Biol., 17:3565-3569 


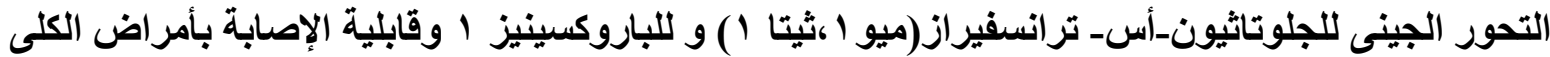

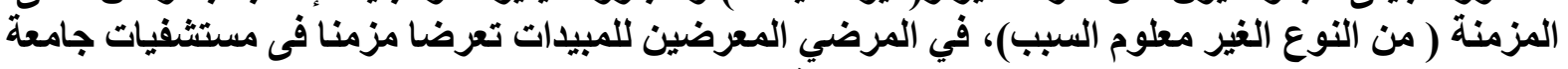
الزقيقازيق

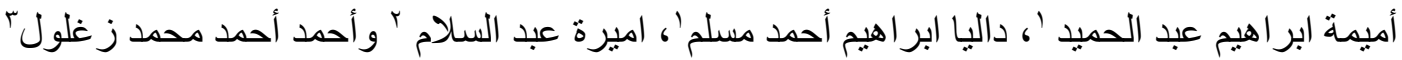

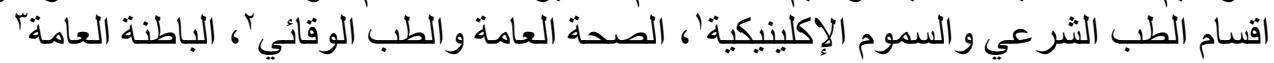

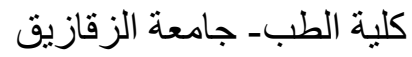

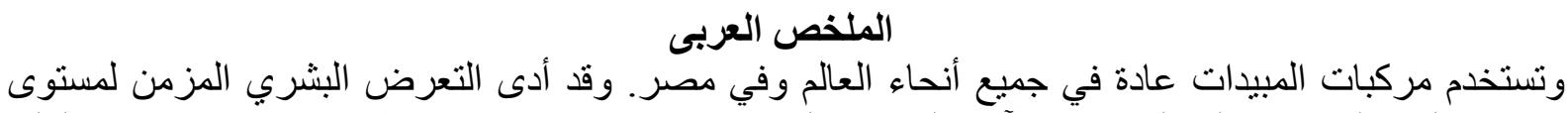

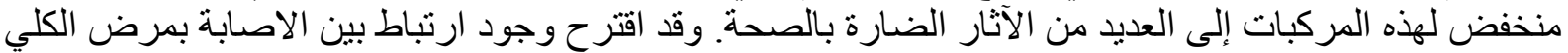

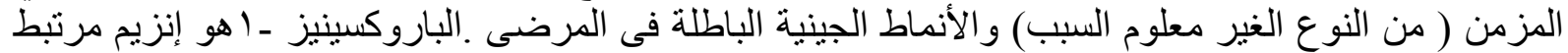

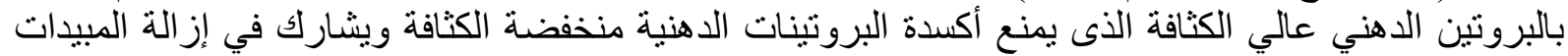

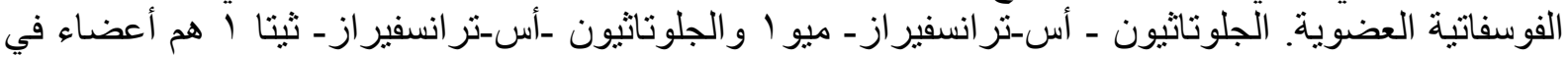

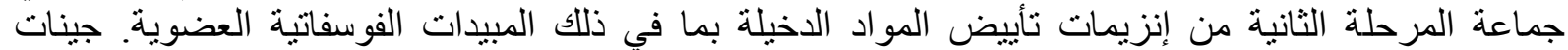

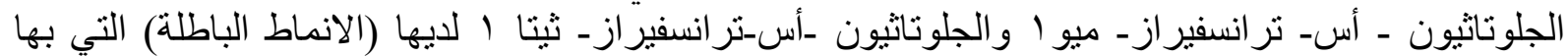
الجين مختفيا بالكاملز

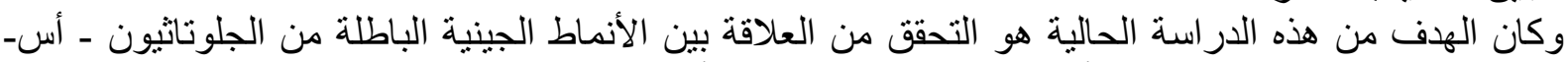

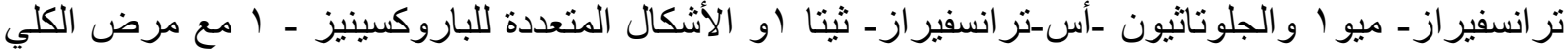

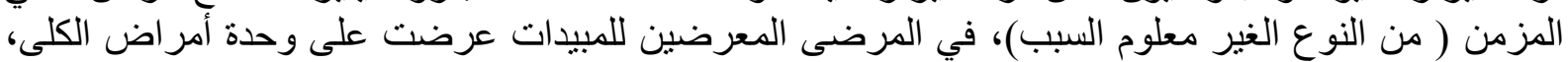

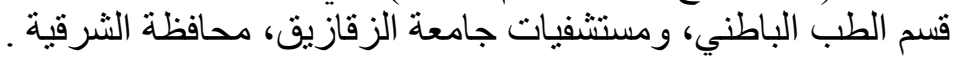
و استخدمت عينات البول للكثف عن الأكيل الفوسفات لأى المرضي المدرجين في الدراسة باستخدام الجهاز

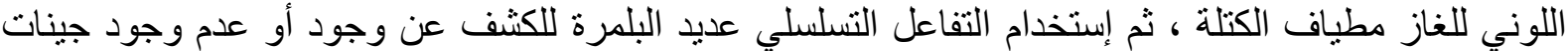

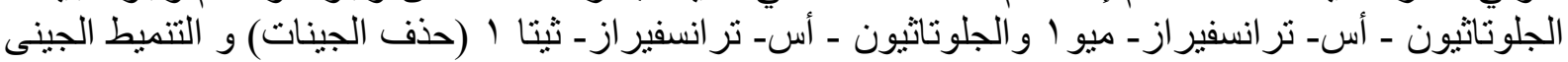

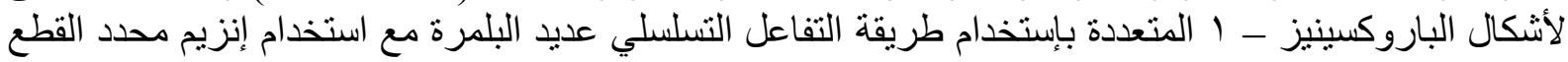
في الحمض النووي الجيني المعزول فى عينات دم من ^ـ مريض كلي مزمن ( من النوع الغير معلوم السبب) لتعرضهم المزمن للمبيدات الحشرية ومطابقتهم للمجمو عة الضابطة.

ـ و أظهرت نتائج هذه الدراسة أن هناك نأثثر للتعرض المزمن للمبيدات الفوسفاتية العضوية علي زيادة احتمالية الاصـابة بمرض الكلي المزمن ( من النوع الغير معلوم السبب) مقارنة بالمجمو عة الضابطة 